increased by various forms of stress such as increased rate of work, fatigue and poor environmental conditions. The possible relationship between the increased static activity imposed by these stresses and myalgia was indicated. Dr. H. Seyffarth (Stockholm) emphasized the importance of ordinary clinical examination in studies such as these; examinations which can afford considerable insight into the conditions of the muscles. Dr. Gerda Seidelin (Copenhagen) also represented the clinical approach and stressed the limitation of activity that can be caused by poor body mechanics inducing pain. The pain may be relieved by the conventional physiotherapeutic methods ; but permanent results are only achieved by correcting the posture, and this can be done only by studying the patient at the work which has produced the condition.

Of the contributions of the applied psychologists, the main emphasis was on the possible application of information theory to the measurement of man's overall performance in complex tasks. The place of the theory in the quantitative prediction of man's responses to known stimuli and vice versa was discussed by Dr. W. E. Hick (Cambridge). He stressed, however, that the position of the theory in this sphere is not clear and that, if established, will not replace more specific methods of investigation. Dr. W. D. Garvey (Washington, D.C.) described experiments in which he obtained a measure of the time necessary for a subject to code information by arranging that the display and response were constant. The results support earlier conclusions that the appropriate coding of information which the subject receives is an important factor in determining how much of it will be usefully dealt with. A different approach to the study of the application of information theory was reported by Mr. E. R. Crossman (Cambridge), who, by the use of a simple card-sorting task, showed that the overall time taken is mainly a function of the amount of choice made.

Illustrating the more specific criteria used in the study of man's performance were the papers of Dr. A. Leonard (Cambridge) and .Dr. Shirley Spragg (Rochester, New York), both of which were concerned with display-control tasks. Dr. Leonard reported on experiments to determine the value of advanced information in such tasks, and Dr. Spragg on the effects of different relationships between the movement of the control and that of the display on tracking performance.

Work study was the subject for discussion at the concluding session. The importance of the practice was stressed because of the part it can play in increasing productivity and in coping with the ageing population; but it was pointed out by Mr. C. R. Wynne-Roberts (London) that, although it is an essential technique, it is only one of those available in industry for increasing individual efficiency. The present stage in the development of work study was outlined by Dr. D. Seymour (Birmingham), who considered that the advances being made are due to the application of pre-existing information rather than to an increase in fundamental data. The latter, though, is essential for the proper development of work study, and some improvement can be achieved by the dovetailing of the work of the psycho-physiologist and the engineer. A rather similar suggestion was put forward by Mr. R. Conrad (Cambridge), who stressed the need for bridging the gap between laboratory investigations and ad hoc studies in the factory. In his opinion, this can be done only by a willingness on the part of the psychologist to take the experimental methods at his disposal on to the shop floor and for the work-study engineer to present appropriate problems for laboratory investigation. Finally, Mr. L. G. Humble (London) gave a picture of the practical problems experienced in applying the results of work study, due to the resistance that is encountered both from the management and from the worker.

\section{INDUSTRY AND THE UNIVERSITIES IN BRITAIN}

\section{CONFERENCE IN NOTTINGHAM}

$T$

HE report of the conference on industry and the universities, organized by the Federation of British Industries North Midland Regional Council and the University of Nottingham, and held at Nottingham on September 24, 1952, has now been published*. It was the sixth regional conference of its kind to be held since the national conference on this subject held in November 1949, and the report includes the text of the following addresses : by Lord Hives on what industry requires from the universities; by Prof. J. A. Pope on whether universities can contribute to the needs of industry; by Sir Edward Herbert on what is the best training for the university student who wants to find a career in industry; and by Dr. F. A. Wells on the study of industrial organization and management as an academic discipline, and the contribution which industry itself can make in this field.

Lord Hives, who began by describing the methods used by Rolls Royce, Ltd., in dealing with an annual intake of about thirty university graduates, emphasized that his firm does not expect the universities to supply ready-made technicians, designers, metallurgists or chemists. It expects the universities to turn out men who are capable of thinking and who have received the basic training in the fundamental sciences essential to their future work; whose brains have been trained to tackle problems; and who, of their own initiative, can follow a problem through, step by step and logically, taking advantage of previous experience on allied work. Furthermore, said Lord Hives, his firm liked good citizens-men who can express themselves well and hold their own in the conference, and can report clearly and concisely on their work. Lord Hives does not believe that the universities can deal with specialized technological education satisfactorily; he is of the opinion that they are too remote from the rapidly changing requirements of industry, and they cannot afford the extensive and complicated equipment used in modern industrial engineering investigations.

For these reasons he said that he is doubtful as to the value of the proposal to establish an institute of technology and inclines to prefer graduates who come direct from their three years at a university to those who come from the Massachusetts Institute of Technology or one of the Continental technological institutes. The engineering industry, is, however, disturbed at the inadequate numbers of men coming from the universities, and Lord Hives suggested that the balance between arts students and those studying science and engineering is out of keeping with the

* Report of the Conference on Industry and the Universities, organ-
sed by the H.B.I. North Midland Regional Council and the University ised by the $\mathrm{H}^{\mathrm{H}}$.B.I. North Midland Regional Council and the University vil +39 . (London: Federation of British Industries, 1953.) 48. 6d. 
demand. He stressed the importance of the appointments officers of the universities and suggested that they deserve better support. As regards quality, more first-class graduates are required and, particularly in the average man, an improvement in quality is desirable.

Sir Edward Herbert's address in some respects overlapped that of Lord Hives. He too agreed that industry recognizes that the first function of a university must always be that single-minded pursuit of learning and continual advance of knowledge which are essential to the existence and growth of a civilized society. The value of a university graduate in industry, or in any other walk of life, lies in the trained and flexible mind which the three or four years of mental discipline may be expected to produce. It does not lie in the possession of any particular body of knowledge, and Sir Edward suggested, in considering what qualities industry looks for in its recruits from the universities, that we should look not at the graduate starting his first job, but at the man he hopes to become at thirty-five or forty on the threshold of major responsibilities. His future would then turn, not on his specialized knowledge but on his capacity to assume responsibility.

Accordingly, Sir Edward thought, industry would seek for such future leaders a combination of threc main categories of ability. First, the ability to equip oneself thoroughly with expert knowledge of the particular aspect of the business in which one is engaged ; this provides the basis of genuine authority. Second is the ability to relate this specialist function to the conduct of the business as a whole, including not merely the problems of the industry but also of the community which that industry serves. The third is the ability to sustain the moral burden of responsibility. Sir Edward made no suggestion as to what formal part the university can hope to take in preparing a man for this last responsibility; but a university should, he thought, be able to foster a lasting regard for other human beings, and it should strive to instil the conception of duty and service. All who hold authority in a community should be constantly aware of the human implications of the decisions they have to make from day to day, but Sir Edward believed that professional training in business administration and management should come some time after the degree course, and not form part of it. Finally, he stressed the immense value of a friendly understanding between the universities and industry and the need for industry to become much more imaginatively alive to its own opportunities and achievements.

The importance of co-operation betweon the universities and industry was also stressed by Prof. Pope, who pointed out that, with the adequate financial assistance now available, practically all able boys and girls from the grammar and secondary schools in Britain are proceeding to a university ; as a consequence, the direct entry into industry from schools has suffered considerably, and this is a problem which has been considered more particularly at a subsequent conference of the Federation of British Industries held last October. Apart from the professional qualifications, Prof. Pope maintained that a university education should discipline a person to be intellectually honest and to be capable of a balanced view of issues as they arrive.

While Dr. Wells also stressed the need for more and closer personal relations between industry and the universities, particularly on the social science side, his address was largely a plea for specific assistance from industry in providing material for economic studies. First, he said, more opportunities are needed for studying the organization of firms and for investigating their problems at first hand. Secondly, there is the desirability of having access to business records, particularly old historical records ; and thirdly, the assistance of industry in developing the method of teaching based on case study. Fourthly, it is desirable to know more about the associations of the business world, such as the Federation of British Industries, the British Employers' Confederation and some of the more important sectional organizations. Far more, he said, is known of the trades union movement than of its counterpart on the employers' side.

\section{SOUTH AFRICAN ASSOCIATION FOR THE ADVANCEMENT OF SCIENCE}

\section{FIFTIETH ANNIVERSARY}

$\mathrm{W}$ HEN the South African Association for the Advancement of Science met last year, during July 7-12, in the buildings of the University of Cape Town, it was to celebrate the golden jubilee of its foundation, for, though the date did not exactly coincide with fifty years, the occasion was fitting in that it was in Cape Town on September 12, 1901, when the constitution of the Association was drawn up, and on April 27, 1903, also in Cape Town, when the first annual meeting was held. The meeting last year, which was under the presidency of Dr. B. F. J. Schonland, of the Bernard Price Institute of Geophysical Research, Johannesburg, was marked by the invitation of the following distinguished guests from overseas : Sir Lawrence Bragg (Cambridge) and Sir Edward Salisbury (Kew Gardens); Prof. L. E. J. Brouwer (Amsterdam) and Prof. J. H. Oort (Leyden); Canon G. Lemaître (Louvain) and Prof. G. Magnel (Ghent); Dr. H. Vallois (Paris); and Prof. A. da Silva Rego (Lisbon). The official representatives of other bodies were as follows: for the sister Associations in Australia and New Zealand and in the United States, Sir Kerr Grant, the Australian physicist, and Dr. J. D. J. Hofmeyr, of Pretoria, respectively ; for the Royal Society of South Africa, the oldest scientific society in the country (which, incidentally, was celebrating its seventy-fifth anniversary), Prof. R. W. James, of the University of Cape Town; and for the Suid-Afrikaanse Akademie vir Wetenskap, Dr. T. E. W. Schumann, director of the Weather Bureau of the Union of South Africa.

The activities of the meeting are recorded in the October-November issue of the Association's journal, the South African Journal of Science, and in this issue are published a brief description of the meeting, Dr. Schonland's presidential address and the texts of eleven papers, included in which are those of overseas visitors-namely, Dr. Vallois, Canon Lemaître, Prof. Oort, Prof. Rego, Sir Lawrence Bragg, Sir Edward Salisbury and Prof. Brouwer.

Dr. Schonland began his address by outlining the inception of the Association under the presidency of Sir David Gill, then H.M. Astronomer at the Cape, and showed how the early enthusiasm of the first meeting, at which $\mathbf{7 0 3}$ full members and 36 associates attended, led to a membership of 1,322 in 1906 , 